This is the peer-reviewed version of the paper:

Pejovic-Milovancevic, M.; Kesic, A.; Grujicic, R.; Stojkovic, A.; Zivotic, S.; Stupar, D.; Borovnica, V.; Radosavljev-Kircanski, J.; Manojlovic, I.; Stojiljkovic, D. J. Inpatient Care in Serbia: Trends in Hospitalization and Diagnostics over Time. Eur Child Adolesc Psychiatry 2018, 27 (12), 1645-1651. https://doi.org/10.1007/s00787-018-1191-3.

\title{
(9) $(1) \Theta$
}

This work is licensed under the Attribution-NonCommercial-NoDerivatives 4.0 International (CC BYNC-ND 4.0) 


\section{Inpatient care in Serbia: trends in hospitalization and diagnostics over time}

\section{Introduction}

First onset of mental disorders usually occurs in childhood or adolescence, although treatment typically does not occur until a number of years later [1]. Mental health problems among children and adolescents are increasing in the last few years, possibly due to drastic changes in lifestyle and habits, heightened awareness among caregivers and parents resulting in increased reporting, or the negative effect of media and globalization [2]. Treatments are available, but nearly two-thirds of children/adolescents with a known mental disorder never seek help from a health professional [3].

The decision when to admit child or adolescent to a mental health hospital for diagnostics and treatment procedures is not an easy step due to multiple reasons: in this vulnerable age hospitalization could have numerous advantages and disadvantages; absence from school as well as from regular social activities could produce further problems in rehabilitation after initial treatment; clinical presentation is often changeable and it is necessary to precisely assess indications and risks during the outpatient's visit(s), as well as availabilities of other possible forms of treatment and stigmatization is still the issue that should be taken into account.

Sometimes short inpatient stay is avoidable and it should be based on medical necessity and the best interests of the patients, and if possible, of their families. Such decisions often involve the cooperation with other professionals (other physicians of different specialities, psychologists, social workers) - mental health team for/around children and adolescents. Patients and their parents/caregivers should be also fully informed participants in the decision of admission and later in the process of treatment.

The use of inpatient psychiatric treatment in a hospital setting when the psychiatric needs of a child or adolescent are justified in certain situations should be provided in high quality [4]. General guidelines for hospitalization of children and adolescents include disorders that significantly disturb everyday patient's functioning and that should not be adequately and safely diagnosed and treated in outpatient setting [5]. Despite the risks, studies show that hospitalizations in child and adolescent psychiatry (CAP) have clear benefits, especially if specialized treatment program and aftercare are available $[6,7]$. The length of treatment, a positive therapeutic alliance, as well as better premorbid family functioning are key predictors of a better outcome of hospital treatment [8]. It might be interesting to note that there are also studies that clearly show that non-clinical variables (i.e., paramedical reasons such as type and location of hospitals, supportive services programs, age, locations of schools and living arrangements) are key predictors of the duration of hospitalization [9].

Hospitalization is just one of many possible services that children or adolescents might need to receive at some point growing up, but the efficacy of this type of treatment is in doubt [10]. For this reason, we need to update our knowledge and understanding of acute mental health treatment and its benefits through thorough research. Better understanding of this subject would provide new strategies and policies that enhance the mental healthcare system in CAP.

The aim of our study was to present trends in inpatient treatment of children and young people in three stationary psychiatric institutions in Belgrade from 1996 to 2015 and to focus on understanding the trends of practice in the child and adolescent psychiatry in Serbia. Estimated number of residents in Republic of Serbia on December 31, 2016 (without 
Kosovo and Metohija) is 7,040,272. There are $19.37 \%$ children and adolescents under 18 years $(1,363,652)$ [11]. The first department for child neuropsychiatry was founded in Belgrade in 1949 [12]. There are four institutions in capital city of Belgrade where children and adolescents are being treated within hospital settings with a capacity of 64 beds and 46 places for day hospitals for children (under 12 years) and adolescents (from 15 to 24) which can accommodate 46 adolescents. There are several inpatient models.

- Day hospital for children (partial hospitalization) — recommended for children from age 3-12 years, with complicated developmental disorders, mostly autistic spectrum disorders.

- Day hospitals for adolescents (partial hospitalization) - intended for adolescents from age 15-25 years with problems in identity formation, adolescent crisis with symptoms of affective, anxiety, stress related, somatoform, behavioral and emotional disorders; this unit is intended for patients with no risk for their safety.

- Day hospitals for treatment of young people from the age 12-18 years with diagnosis of polytoxicomania.

- Inpatient units for children and adolescents - two models are present-one type provides treatment for children and adolescents up to 18 years (children up to 8 years are admitted to the hospital accompanying by parent/ caregiver); another type of units provides treatment only

for adolescents from the age of 15-24 years with special treatment program for adolescents with eating disorders.

- Psychiatric unit for acute emergencies - provides care and treatment for those adolescents (age 14-18) who need $24 \mathrm{~h}$ monitoring because of high suicidal risk (including suicide

attempt) and/or risk of serious self-mutilation and adolescents in psychotic decompensation and other acute mental states with reduced capacity to control their own behavior.

In this article, we analyze the frequency, duration of hospitalization, and the number of diagnoses over the period of 19 years based on data from three stationary psychiatric institutions in Belgrade (the fourth institution has been opened recently). The data from these types of a study formats are primarily illustrative/useful for understanding the status of child and adolescent psychiatry in our community, as well as trends in diagnosis (issue of number of diagnosis/comorbidities) and hospital treatment (in terms of frequency and duration of hospitalization, as well as interrelations of these variables).

\section{Methods}

\section{Participants}

Database consists of 6705 patients from three different mental health institutions in Serbia. Patients were aged from 0 to 18 years $(\mathrm{AS}=12.96, \mathrm{SD}=5.27), 51.5 \%$ female.

\section{Measures}

Variables that were collected are as follows: gender and age, the length of hospitalization (AS $=23.29, \mathrm{SD}=19.79)$ and the number of diagnoses $(\mathrm{AS}=1.29, \mathrm{SD}=0.62)$.

\section{Research design}

For this research, we used some databases from three institutions in Belgrade, Serbia. Data were collected from 1996 to 2015 within the departments for CAP. 


\section{Statistical analysis}

Statistical data processing techniques used in the research, except descriptive statistics, are linear regression and Spearman's rank correlation. Since data, as expected, are not distributed according to the normal curve model, for testing the connection and trends we used Spearman's rank correlation. For testing prediction we used simple and multiple linear regression models.

\section{Results}

In Table 1, we showed the frequency of certain categories of diagnoses registered between 1996 and 2015. The highest percentage of diagnoses is noted within the category behavioral and emotional disorders with onset usually occurring in childhood and adolescence $(21.0 \%)$, pervasive and specific developmental disorder (14.6\%) and anxiety, dissociative, stress related, somatoform and other nonpsychotic mental disorders (13.4\%).

Considering these results, we examined correlation between years of admission and number of diagnoses within these categories. Of all patients in database, there are $25.6 \%$ of patients having at least one diagnosis in category of behavioral and emotional disorders. Results show that in later years, this diagnosis has become more frequent $(r=0.854, p<0.01)$. Of all patients in database, there are $16.6 \%$ patients having at least one diagnosis in category of anxiety, dissociative, stress related, somatoform and other nonpsychotic mental disorders. Although, trend of increase or reduction is not observed $(r=-0.111, p=0.64)$. Other diagnoses that are noted belong to categories that do not indicate mental disorders, but these diagnoses sometimes occur with them. Of all patients in database, there are $16.4 \%$ patients having at least one diagnosis which does not belong to the mental, behavioral and neurodevelopmental disorders, and there is a trend of increasing number of these diagnoses $(r=0.647, p<0.01)$. In Fig. 1, we showed numbers of these diagnoses per year of admission.

An interesting fact is that of $18.3 \%$ patients have at least one diagnosis within pervasive and specific developmental disorders; there are $44.3 \%$ having pervasive developmental disorders diagnoses. In Fig. 2, we present number of pervasive and specific developmental disorders diagnoses (F80-F89) per year, and number of pervasive disorders only (F84.0 F84.9), where we can notice a sudden rise in the number of these diagnoses since year 2005 and less variation until year 2005 in case of number of pervasive disorders diagnoses. Results showed trend of increase in number of pervasive disorders diagnoses with year of admission $(r$ $=0.657, p<0.01)$.

In Fig. 3, we present the number of patients in each year. Results showed that number of patients has increased over the years $(F(1,17)=37.890, b=8.114, t=6.155, p<0.01)$. This model explains $69.0 \%$ of variance, but we can notice peaks and oscillations in Fig. 3, so it is not certain whether this upward trend would continue after year 2015.

The results have shown that there is weak, but significant negative correlation between year of admission and length of hospitalization $(r=-0.160, p<0.01)$ and patients age $(r=-$ $0.049, p<0.01)$. Also, there is positive correlation between year of admission and number of diagnoses $(r=0.231, p<0.01)$. Therefore, over time, hospitalization length became shorter and the average age of patient decreased, while the number of diagnoses increased. Also, hospitalization length correlates positively with patient's age $(r=0.306, p<0.01)$, which leads to the conclusion that the older respondents were hospitalized longer. As for the gender differences, female patients were hospitalized longer than male patients ( $\mathrm{rpbis}=0.132, p<$ $0.01)$.

Two more trends were observed. First, hospitalization length had been decreasing over the years $(r=0.160, p<0.01)$. Another trend showed that number of diagnoses is increasing 
over the years $(r=0.231, p<0.01)$. In addition, multiple regression model explained $10.1 \%$ of variance in hospitalization length $(F(4,5765)=162.524, p<0.00)$. Significant predictors of hospitalization length are the age of patients $(\beta=0.227, t=18.207, p<0.01)$, year of admission $(\beta=-0.223, t=-17.342, p<0.01)$, gender $(\beta=0.049, t=3.942, p<0.01)$ and number of diagnoses $(\beta=0.045, t=3.523, p<0.01)$.

Table 1 Percentage of certain diagnoses category

\begin{tabular}{|c|c|c|c|}
\hline Code & Category & Number & $\%$ \\
\hline F00-F09 & Mental disorders due to known physiological conditions & 43 & 0.5 \\
\hline F10-F19 & Mental and behavioral disorders due to psychoactive substance use & 65 & 0.8 \\
\hline F20-F29 & Schizophrenia, schizotypal, delusional, and other non-mood psychotic disorders & 954 & 11.0 \\
\hline F30-F39 & Mood (affective) disorders & 718 & 8.3 \\
\hline F40-F49 & Anxiety, dissociative, stress related, somatoform and other nonpsychotic mental disorders & 1160 & 13.4 \\
\hline F50-F59 & Behavioral syndromes associated with physiological disturbances and physical factors & 362 & 4.2 \\
\hline F60-F69 & Disorders of adult personality and behavior & 109 & 1.3 \\
\hline F70-F79 & Intellectual disabilities & 897 & 10.4 \\
\hline F80-F89 & Pervasive and specific developmental disorders & 1264 & 14.6 \\
\hline F90-F98 & Behavioral and emotional disorders with onset usually occurring in childhood and adolescence & 1821 & 21.0 \\
\hline F99 & Unspecified mental disorder & 1 & 0.0 \\
\hline Other & & 1258 & 14.5 \\
\hline
\end{tabular}

Fig. 1 Number of diagnoses within these three categories per year

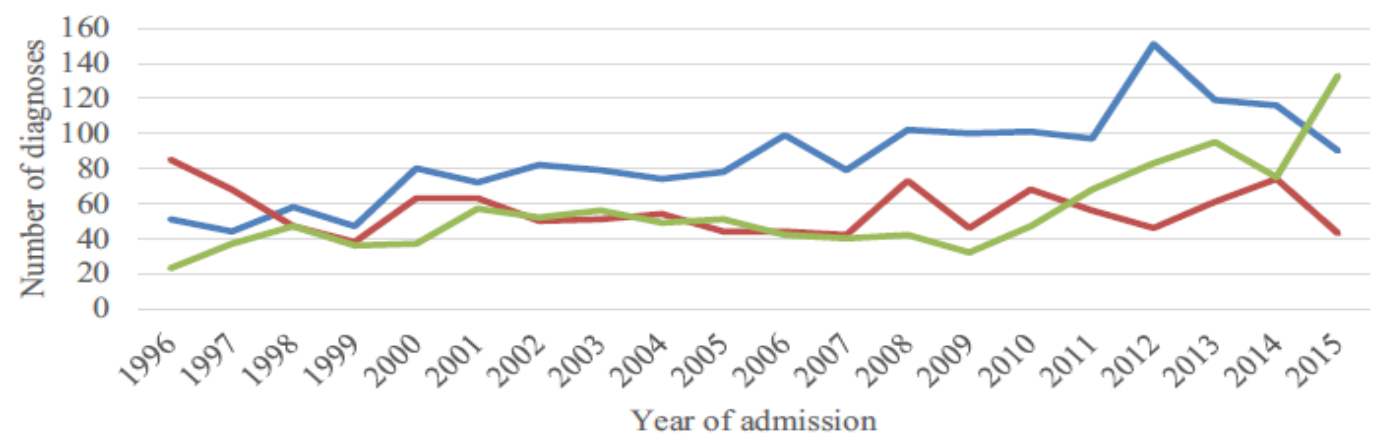

Behavioral and emotional disorders with onset usually occurring in childhood and adolescence (F90-F98)

Anxiety, dissociative, stress-related, somatoform and other nonpsychotic mental disorders (F40-F49)

other non-mental disorder diagnoses 


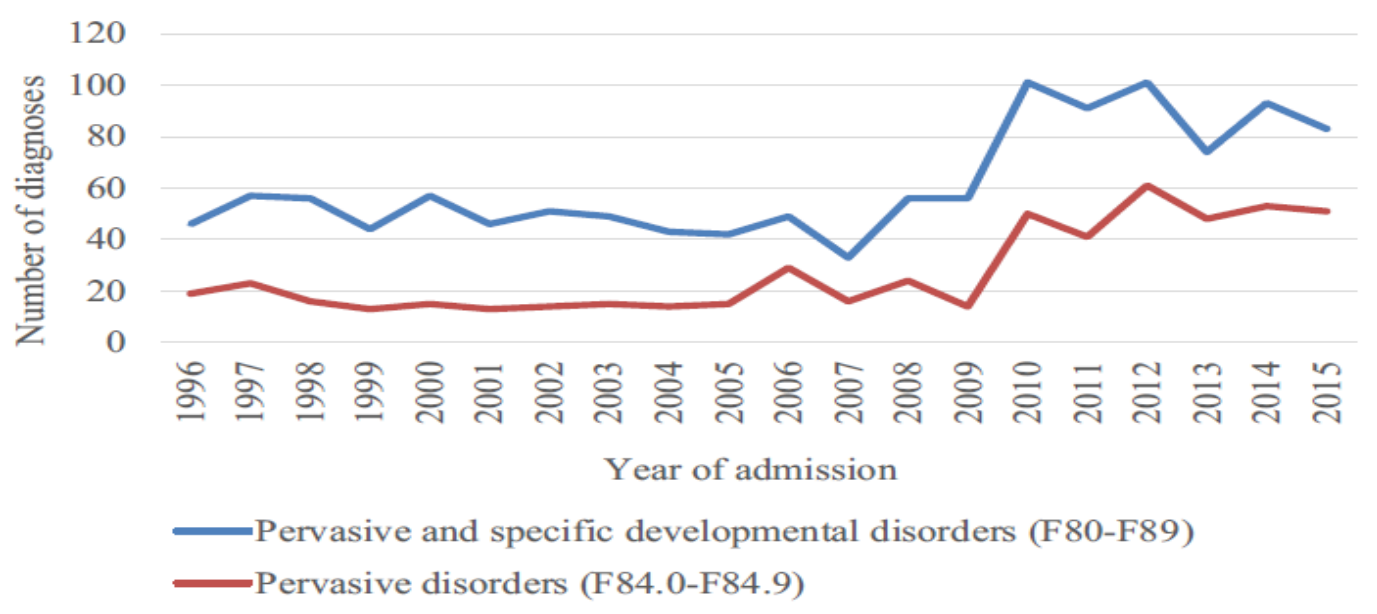

Fig. 2 Percentage of diagnoses within pervasive and specific developmental disorder and pervasive disorder only categories per year

\section{Discussion}

This article shows time change in hospitalization pattern in three largest mental health institutions for the treatment of children and adolescents in Serbia. We summarize all inpatient records from 1996 to 2015: frequency of certain categories of diagnoses; the number of patients in each year; length of hospitalization; trends and predictors of length of stay in inpatient settings. To our knowledge, this is the first study describing CAP hospitalizations in a nationally representative sample from three of the biggest CAP institutions in our country.

First group of results are regarding the common diagnoses; according to the results of our study the three most common diagnoses registered for hospitalized patients were behavioral and emotional disorders, pervasive and specific developmental disorders and anxiety, dissociative, stress related, somatoform and other nonpsychotic mental disorders. Recent studies conducted in several countries show similar results emphasizing developmental disorders, mental retardation and organic brain disorders, attention deficit/ hyperactivity disorder and anxiety disorders as the most common diagnoses at inpatient and outpatient CAP clinics [13-15]. There is a noticeable and significant increase in number of pervasive developmental disorder diagnoses per year in our institutions, which was not surprising owing to the fact that there is a great number of researchers in CAP field that reported the same situation in different parts of the world [16-18]. Most probable contributors to the rise of prevalence are: changes in classification, changing and updating diagnostic procedures, improving service availability through years, better acceptance and awareness of parents and surroundings. 


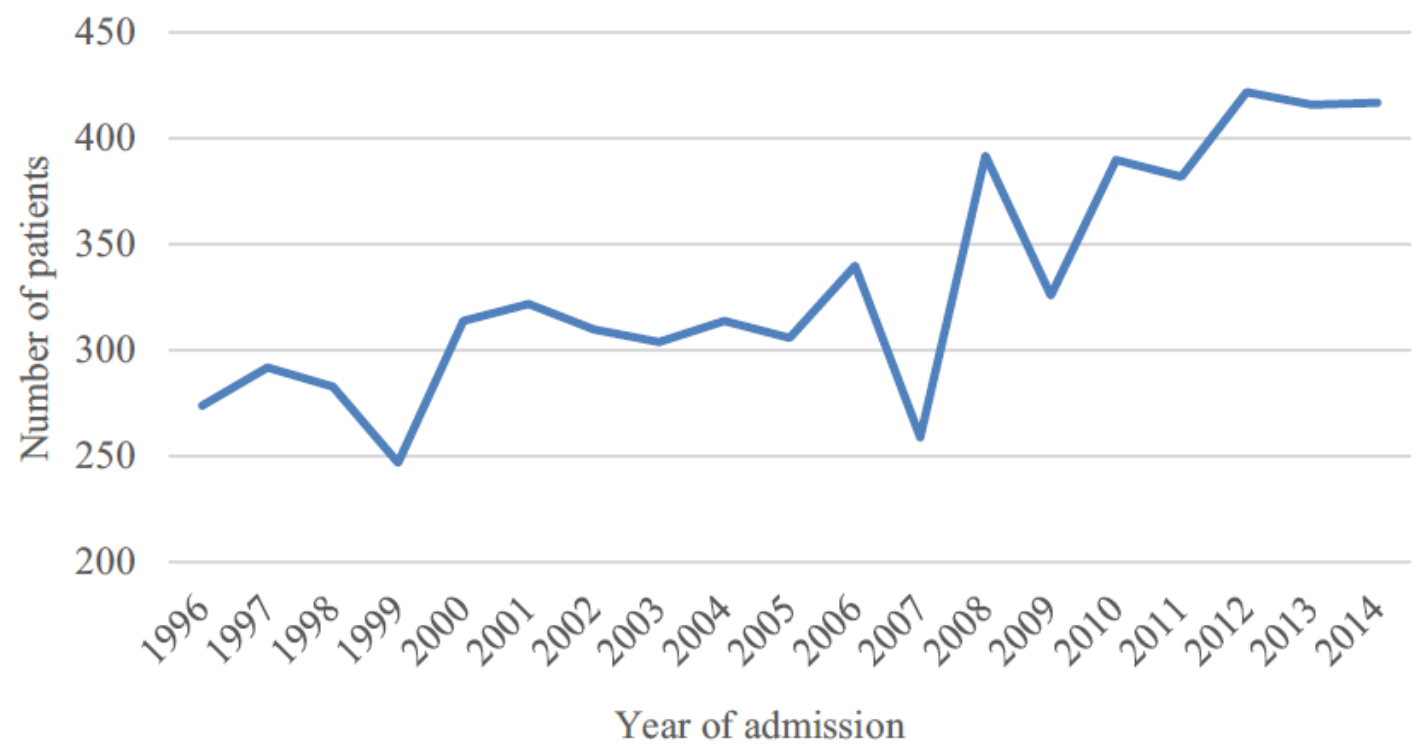

Fig. 3 Patient's number per year of hospitalization

Second group of findings show that the effects of hospital care and the length of stay are important for mental health policy. While the majority of people with mental health conditions will not need to spend time in a hospital or treatment center, sometimes there is a need for hospitalization due to a need for close monitoring, accurate diagnosis, need for adjusting or stabilizing medications, etc. [19]. Unfortunately, in Serbia most of the care centers are located in big cities and centers that are usually far away from patients' homes, so patients need to stay at hospitals because they cannot get proper care in their hometown. Our results show that over time the number of hospitalized patients was growing, and the length of hospitalization had a decreasing trend. This finding was expected for our country, mostly owing to the fact that we have a lot of patients and their families who live far away and they travel to tertiary centers for quick assessment, after which the treatment usually continues in their community hospitals/outpatient units. Even if this is not the case, we tend to follow worldwide recommendations for hospitalizations in CAP care, that advise shorter hospital stay, and start resocialization process as soon as possible [20]. Kathleen et al. presented almost identical findings: during the study period there was increase in hospital discharges, decline in mean length of stay and decline in the number of bed days [21]. The other study does not find changes in number of hospitalizations, but demonstrates a clear trend of decline of median length of stay from 12.2 to 4.5 days during the decade 1990-2000 (which was notably shorter than in our environment) [22]. On the other hand, the study of trends in outpatient treatment of children and adolescents in the United States shows an increase in the use of non-hospital forms of treatment, as well as psychotropic medications [23].

In recent years the diagnostic procedure is faster due to wider use of valid diagnostic procedures (better and frequent use of standard instruments, better team coordination, more well-educated professionals capable of fulfilling all procedures in faster and proper manner, etc.). The emphasis of inpatient psychiatric treatment has shifted from detailed assessment and treatment to a brief and intensive intervention [24]. There is also growing trend in better reliability among services of support, such as social, educational and healthcare systems which actually decrease the need for longer stay in hospital, so children and adolescents are dismissed from hospital as soon as they get better and are thoroughly followed in outpatient settings. 
Better connections among professionals from different backgrounds and better regional relations would also contribute to shorter hospital stay [25].

Our study also shows that older patients stay longer in hospitals and the reasons might be discussed in a way that the nature of problems in early adolescence needs longer treatment procedure; younger children are usually admitted due to diagnostic procedures and due to treatment of comorbid conditions. On the contrary, adolescents are included in procedures that need longer assessment and follow-up. Also, girls stay longer than boys and these findings are due to more frequent internalizing problems among girls generally, comparing to boys, but also due to the specific inpatient unit in one of three assessed institutions where eating disorders are treated frequently and their hospital treatment lasts longer than treatment of some other disorder.

Most of the literature suggests that shorter rather than longer stays were more effective for most psychiatric disorders [19] (but the shorter stays in these studies would qualify as longer stays today). However, the average stay in our clinics is approximately 2 weeks and we agree with the point made in recent review of the literature from Europe [26] that "there has been some unsettling evidence to suggest that shortening hospital stays may not be a general panacea". To cut down on cost, many countries have shortened hospital stay for patients with serious mental illnesses. Such practices have been noticed in those countries with higher GDP, where in the past 30 years the length of hospital stay has been significantly reduced [27]. We support the idea to individualize treatment depending on the patient's condition, his or her previous treatment experience, and the family and other resources available to support the treatment, etc.

Another important finding is that in later years of the examined time frame children are assessed earlier and the diagnoses are established in earlier ages. Initial onset of mental disorders usually occurs in childhood or adolescence. It is thought that early interventions with early onset cases might contribute to better therapeutic response, decrease disease severity, as well as prevent or delay onset of secondary disorders [28]. An examination of age of onset distributions is important for at least three reasons. Comprehensive understanding of age of onset of mental health problems is important for targeting research on prevention of mental disorders [29], early intervention with prodromal or incipient mental disorders [30] and primary prevention of secondary disorders [31].

We also found that over time the number of diagnoses is increasing. One of the reasons could be better recognition of mental health problems among children and youth, but also recognition of conditions such as abuse and neglect, problems in social environment, etc. With development of CAP in Serbia we have younger professionals who follow recommendations and establish the diagnoses according to the valid classification systems.

Finally, we have shown that significant predictors of hospitalization length are the age of patient, the year of admission and number of diagnoses. Over time hospitalization length in Serbia had a decreasing trend, and it was not surprising that year of admission was a predictor of hospitalization length. Previous studies have shown same results that age and severity of patient's condition are the most constant predictors of longer stay in psychiatric hospital units [32-34].

Our study has several limitations. First of all, study is restricted to diagnoses and length of stay at inpatient units, so it does not show information regarding usage of pharmacotherapy, duration of treatment, which medications are intended to treat which disorders and type of psychotherapy provided. Showing treatment or assessment data would provide more complete portrayal of trends we observed. Also, our study was focused on three of the biggest CAP tertiary care institutions in our country. It does not capture visits to community health centers, or other inor outpatient units in other parts of our country, which are more accessible for lowincome families that live far away. 


\section{Conclusion}

The importance of identifying and targeting problems in children and early adolescence is strengthened by the fact that $50 \%$ of mental health problems present themselves before the age of 14. The research also shows that effective treatment can reduce the risk of such consequences. Early identification, accurate diagnosis and effective treatment of mental health problems can alleviate the burden of children, adolescents and their families. Providing early care can help young people to recover more quickly and benefit from their education, to develop positive relationships, to gain access to employment, and ultimately to lead more meaningful and productive lives.

Future research should be focused on better comprehension of acute mental health problems in children and adolescents so the system that provides mental care can be enhanced with new strategies and policies. If the necessity of inpatient units is to remain recognized, it will be essential to demonstrate what they offer over and above communitybased care, and why they are fundamental part of child mental health provision.

Acknowledgements The authors want to thank to Prim. Dr. Vojislav Curcic, Prof. Dr. Aneta Lakic and Prof. Dr. Dusica Lecic-Tosevski for their support

\section{References}

1. Kessler RC, Amminger GP, Aguilar-Gaxiola S, Alonso J, Lee S, Ustun TB (2007) Age of onset of mental disorders: a review of recent literature. Curr Opin Psychiatry 20(4):359-364

2. Ahmad N, MuhdYusoff F, Ratnasingam S, Mohamed F, Nasir NH, MohdSallehuddin S et al (2015) Trends and factors associated with mental health problems among children and adolescents in Malaysia. Int J Cult Ment Health 8(2):125-136

3.WHO|Mental disorders affect one in four people (2013) WHO [Internet]. http://www.who.int/whr/2001/media centr e/press_relea se/en/. Accessed 24 Jan 2018

4. Signorini G, Singh SP, Marsanic VB, Dieleman G, DodigĆurković K, Franic T et al (2018) The interface between child/ adolescent and adult mental health services: results from a European 28-country survey. Eur Child Adolesc Psychiatry 27(4):501-511

5. World Health Organization (2003) Caring for children and adolescents with mental disorders Setting WHO directions. World Health Organization, Geneva

6. Lee Y, Martin P, Hembry P, Lewis S (2017) Outcomes of inpatient psychiatric treatment for adolescents: a multiple perspectives evaluation. Clin Child Psychol Psychiatry $1: 135910451773907$

7. Blanz B, Schmidt MH (2000) Preconditions and outcome of inpatient treatment in child and adolescent psychiatry. J Child Psychol Psychiatry 41(6):703-712

8. Green J, Jacobs B, Beecham J, Dunn G, Kroll L, Tobias C et al (2007) Inpatient treatment in child and adolescent psychiatry - a prospective study of health gain and costs. J Child Psychol Psychiatry

48(12):1259-1267 
9. Leon SC, Snowden J, Bryant FB, Lyions JS (2006) The hospital as predictor of children's and adolescents' length of stay. J Am Acad Child Adolesc Psychiatry 45(3):322-328

10. Pumariega AJ, Winters NC, Huffine C (2003) The evolution of systems of care for children's mental health: forty years of community child and adolescent psychiatry. Community Ment Health J 39(5):399-425

11. Statistical Office of the Republic of Serbia (2011) Population of Serbia [Internet]. http://webrz s.stat.gov.rs/WebSi te/Publi c/PageV iew.aspx?pKey=162. Accessed 24 Jan 2018

12. Remschmidt H, Engeland H (1999) Child and adolescent psychiatry in Europe: historical development current situation future perspectives. Steinkopff, Darmstadt

13. Zima BT, Rodean J, Hall M, Bardach NS, Coker TR, Berry JG (2016) Psychiatric disorders and trends in resource use in pediatric hospitals. Pediatrics 138(5):e20160909

14. Malhotra S, Biswas P, Sharan P, Grover S (2007) Characteristics of patients visiting the child \& adolescent psychiatric clinic: a 26-year study from North India. Child Adolesc Ment Heal 3(3):53-60

15. Yazar S, Corresponding Doç A, Coşkun M, Kliniğine P, Okulöncesi B et al (2016) Prevalence and patterns of psychiatric disorders in preschool children referred to an outpatient psychiatry clinic. Anadolu Klin Ocak Cilt 21(1):42-47

16. Van Bakel MME, Delobel-Ayoub M, Cans C, Assouline B, Jouk P-S, Raynaud J-P et al (2015) Low but increasing prevalence of autism spectrum disorders in a French area from register-based data. J Autism Dev Disord 45(10):3255-3261

17. May T, Sciberras E, Brignell A, Williams K (2017) Autism spectrum disorder: updated prevalence and comparison of two birth cohorts in a nationally representative Australian sample. BMJ Open 7(5):e015549

18. Hansen SN, Schendel DE, Parner ET (2015) Explaining the increase in the prevalence of autism spectrum disorders. JAMA Pediatr 169(1):56

19. Glick ID, Sharfstein SS, Schwartz HI (2011) Inpatient psychiatric care in the 21st century: the need for reform. Psychiatr Serv 62(2):206-209

20. Indig D, Gear C, York A (2017) The role of inpatient care for children and adolescents with moderate-to-severe mental disorders: an evidence check rapid review brokered by the Sax Institute (http://www.saxin stitu te.org.au) for the NSW Ministry of Health. Accessed 7 May 2018

21. Pottick KJ, McAlpine DD, Andelman RB (2000) Changing patterns of psychiatric inpatient care for children and adolescents in general hospitals, 1988-1995. Am J Psychiatry 157(8):1267-1273 
22. Case BG, Olfson M, Marcus SC, Siegel C (2007) Trends in the inpatient mental health treatment of children and adolescents in US community hospitals between 1990 and 2000. Arch Gen Psychiatry 64(1):89

23. Olfson M, Druss BG, Marcus SC (2015) Trends in mental health care among children and adolescents. N Engl J Med 373(11):1078-1079

24. Rössler W (2006) Psychiatric rehabilitation today: an overview. World Psychiatry 5(3):151-157

25. Signorini G, Singh SP, Boricevic-Marsanic V, Dieleman G, Dodig-Ćurković K, Franic T et al (2017) Architecture and functioning of child and adolescent mental health services: a 28country survey in Europe. Lancet Psychiatry 4(9):715-724

26. Capdevielle D, Ritchie K, Villebrun D, Boulenger J-P (2009) Durées d'hospitalisation des patients souffrant de schizophrénie: facteurs cliniques de variations et leurs conséquences. Encephale 35(1):90-96

27. Babalola O, Gormez V, Alwan NA, Johnstone P, Sampson S (2014) Length of hospitalisation for people with severe mental illness. Cochrane Database Syst Rev (1):CD000384

28. Jairam R, Walter G (2014) Early intervention in childhood disorders. In: Early intervention in psychiatry. Wiley, Chichester. Pp 218-33

29. Amminger GP, Leicester S, Yung AR, Phillips LJ, Berger GE, Francey SM et al (2006) Early-onset of symptoms predicts conversion to non-affective psychosis in ultra-high risk individuals. Schizophr Res 84(1):67-76

30. Klosterkötter J, Ruhrmann S, Schultze-Lutter F, Salokangas RKR, Linszen D, Birchwood $M$ et al (2005) The European prediction of psychosis study (EPOS): integrating early recognition and intervention in Europe. World Psychiatry 4(3):161-167

31. Kendall PC, Kessler RC (2002) The impact of childhood psychopathology interventions on subsequent substance abuse: policy implications, comments, and recommendations. J Consult Clin Psychol 70(6):1303-1306

32. Bardach NS, Coker TR, Zima BT, Murphy JM, Knapp P, Richardson LP et al (2014) Common and costly hospitalizations for pediatric mental health disorders. Pediatrics 133(4):602-609

33. Gopalakrishna G, Ithman M, Malwitz K (2015) Predictors of length of stay in a psychiatric hospital. Int J Psychiatry Clin Pract 19(4):238-244

34. Ithman MH, Gopalakrishna G, Beck NC, Das J, Petroski G (2014) Predictors of length of stay in an acute psychiatric hospital. J Biosaf Heal Educ 2(2):1-4 